\title{
Effect of Detergents on Morphology, Size Distribution, and Concentration of Copolymer-Based Polymersomes
}

Pawel Górecki, Radosaw; Antenucci, Fabio; Norinkevicius, Karolis; Elmstrøm Christiansen, Line; Myers, Scott Treven; Trzasku, Krzysztof; Hélix-Nielsen, Claus

\section{Published in:}

Langmuir

Link to article, DOI:

10.1021/acs.langmuir.0c03044

Publication date:

2021

Document Version

Peer reviewed version

Link back to DTU Orbit

Citation (APA):

Pawel Górecki, R., Antenucci, F., Norinkevicius, K., Elmstrøm Christiansen, L., Myers, S. T., Trzasku, K., \& Hélix-Nielsen, C. (2021). Effect of Detergents on Morphology, Size Distribution, and Concentration of

Copolymer-Based Polymersomes. Langmuir, 37(6), 2079-2090. https://doi.org/10.1021/acs.langmuir.0c03044

\section{General rights}

Copyright and moral rights for the publications made accessible in the public portal are retained by the authors and/or other copyright owners and it is a condition of accessing publications that users recognise and abide by the legal requirements associated with these rights.

- Users may download and print one copy of any publication from the public portal for the purpose of private study or research.

- You may not further distribute the material or use it for any profit-making activity or commercial gain

- You may freely distribute the URL identifying the publication in the public portal 
1 Title: Effect of detergents on morphology, size distribution and concentration of copolymer-

\section{Author list:}

5 Radosław Górecki* a, b, Fabio Antenucci ${ }^{\mathrm{c}}$, Karolis Norinkevicius ${ }^{\mathrm{d}}$, Line Elmstrøm

6 Christiansen $^{\mathrm{b}}$, Scott Treven Myers ${ }^{\mathrm{b}}$, Krzysztof Trzaskuś ${ }^{\mathrm{b}}$, Claus Hélix-Nielsen ${ }^{\mathrm{a}}$

7

$8{ }^{\text {a }}$ Technical University of Denmark, Department of Environmental Engineering, Bygningstorvet 115,

92800 Kongens Lyngby

$10 \quad{ }^{\mathrm{b}}$ Aquaporin A/S, Nymøllevej 78, 2800 Kongens Lyngby, Denmark

$11{ }^{\mathrm{c}}$ University of Copenhagen, Department of Veterinary and Animal Sciences, Dyrlægevej 88, 1870

12 Frederiksberg C, Denmark

$13{ }^{\mathrm{d}}$ Technical University of Denmark, Department of Chemical and Biochemical Engineering, Søltofts

14 Plads 228A, 2800 Kongens Lyngby

15

* Corresponding author: rgor@env.dtu.dk; rgo@aquaporin.com

17

TOC/Abstract Graphic:

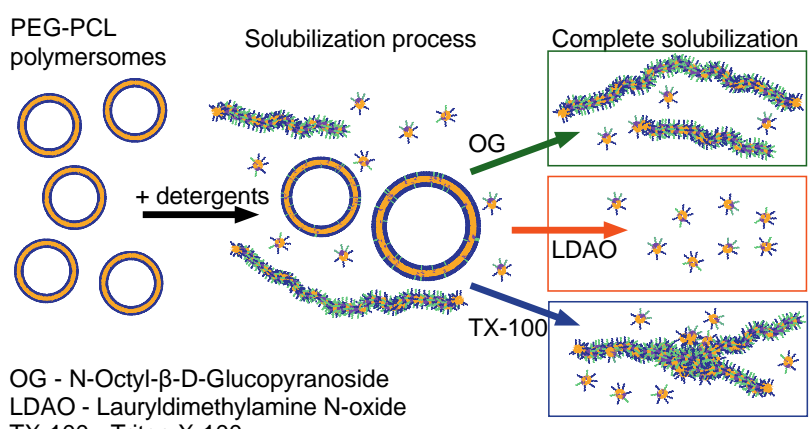




\section{Abstract}

22 Polymersomes made of amphiphilic diblock copolymers are generally regarded as having

23 higher physical and chemical stability than liposomes composed of phospholipids. This

24 enhanced stability arises from the higher molecular weight of polymer constituents. Despite

25 their increased stability, polymer bilayers are solubilized by detergents in a similar manner to

26 lipid bilayers. In this work, we evaluated the stability of poly(ethylene glycol)-block-poly( $\varepsilon-$

27 caprolactone) (PEG-PCL) based polymersomes exposed to three different detergents: N-Octyl-

28 b-D-Glucopyranoside (OG), Lauryldimethylamine N-oxide (LDAO), and Triton X-100 (TX-

29 100). Changes in morphology, particle size distribution, and concentrations of the

30 polymersomes were evaluated during the titration of the detergents into the polymersome

31 solutions. Furthermore, we discussed the effect of detergent features on solubilization of the

32 polymeric bilayer and compared it to the results reported in the literature for liposomes and

33 polymersomes. This information can be used for tuning the properties of PEG-PCL

34 polymersomes for use in applications such as drug delivery or protein reconstitution studies. 
Introduction

37 Amphiphilic diblock and triblock copolymer macromolecules, comprising of hydrophilic and hydrophobic blocks, are known to assemble into supramolecular structures such as micelles, polymer vesicles (polymersomes), rod-like micelles, or planar membranes. ${ }^{1,2}$. There is a strong interest to use these supramolecular assemblies in various research and industrial purposes as they closely mimic their biological equivalents, amphiphilic phospholipids and their selfassemblies (liposomes). Targeted and controlled release of an encapsulated drug payload is the most commonly studied medical application, but polymersomes are also used to study the reconstitution of transmembrane proteins within the membrane layer of the assembly for the preparation of selective separation devices and sensors ${ }^{1,3-9}$. Polymersomes are a promising nanoscale assembly for targeted therapy and treatment of severe disorders, including cancer ${ }^{2}$, due to their improved stability in comparison to micellar structures ${ }^{10}$ and liposomes ${ }^{1}$. The superior chemical and physical stability of polymersomes over liposomes is due to the higher molecular weight (MW) of amphiphilic block copolymer chains, which form a thicker and more rigid bilayer ${ }^{1,11}$ when they self-assemble into vesicles.

Another type of amphiphilic molecule - detergents - can be introduced to the liposome or polymersome solution to change the properties of the self-assemblies; such as morphology, bilayer permeability, and particle size distribution ${ }^{9,12,13}$. Despite the enhanced stability of polymersomes, higher membrane viscosity, and a larger bending modulus (as compared to liposomes ${ }^{14-17}$ ), polymersomes can also be solubilized by detergents. The detergent molecules are inserted into the bilayer structure, which causes a change in the amphiphile packing, rearangment of the bilayer curvature, and ultimately, at a high enough detergent concentration, complete disassembly of the vesicles ${ }^{9,14,18,19}$.

60 
61 Several bilayer solubilization mechanisms have been described, and while they all have minor

62 variations, the general consensus is that the solubilization is a three stage process ${ }^{19-22}$. In the

63 first stage, the detergents migrate into the bilayer, resulting in an increase in vesicle size. In

64 the second stage, when the saturation point of detergents in the bilayer is achieved, the

65 transition from vesicular to mixed micellar structures is initiated. In the third stage of 66 solubilization, a complete transition of the vesicles to mixed micelles, consisting of amphiphiles and detergents, takes place and further addition of detergent only leads to the reduction of the phospholipid/polymer concentration within the mixed micelles 9,19,20,22-24.

Multiple studies investigating the mechanism of liposome solubilization have shown that the concentration of detergents required to solubilize liposome vesicles is dependent on two factors, including (1) the composition of the phospholipids used to construct the liposomal lipid bilayer, and (2) the type of detergent used for solubilization $9,14,27-29,18,20-26$. In contrast to published studies regarding solubilization of liposomes, there is a limited number of publications that focus on the explanation of the solubilization effect on the block copolymerbased vesicle systems ${ }^{30,31}$. Moreover, the studies are often limited to optical density (OD) measurements and dynamic ligtht scattering (DLS) analysis ${ }^{26}$, with visualization made on giant unilamellar vesicles ${ }^{24,30,32}$. DLS is known to have significant drawbacks for proper analysis of polydisperse solutions, as occurs with vesicles mixed with detergents ${ }^{33-38}$.

80 Therefore, DLS analysis as a stand-alone method only partially describes the processes of 81 vesicle solubilization and does not provide any information on particle concentrations or changes in vesicle morphology. As a result, conclusions based solely on DLS measurements

83 are often inaccurate and vague. Very few studies complement OD and DLS analysis of nanostructures with cryogenic transmission electron microscopy (cryoTEM), which allows the

85 visualization of the changing morphologies of the self-assemblies $9,21,27,39$. However, when the 
concentrations of the studied particles drop, it becomes more difficult to visualize the system properly, as very few of the particles will be retained on the TEM grid. Additionally, cryoTEM provides only qualitative and not quantitative information about the particle size distribution and concentrations, thus, only partially explaining the solubiliation mechanism ${ }^{9}$. In the most detailed study on detergent solubilization of polymeric bilayers, Pata et al. investigated the solubilization of polymeric membranes made of poly(ethylene glycol)-block-poly(ethyl ethylene) (PEG-PEE) and poly(ethylene glycol)-block-poly(butadiene) (PEG-PB) block copolymers with Triton X-100 (TX-100) ${ }^{30}$. The authors based their conclusions on OD and DLS measurements that were combined with visualized solubilization of giant unilamellar vesicles. As a result, the morphological transformations occurring in the nanostructures, the changes in particle concentration, and the nanoparticle size distribution analysis were neglected, as was the quantitative overview on the solubilization process. Furthermore, the study was limited to one detergent type (TX-100), thus there is still ample opportunity to broaden the understanding of the effect of detergent type on the process of solubilization of

100 polymer-based bilayers. Finally, the mentioned studies were made on PEG-PEE and PEG-PB

101 based systems and it can be expected that block copolymer bilayers of different compositions will not behave in the same manner upon introduction to different detergent types, similar to membranes composed of different phospholipids. This could, theoretically, allow one to modify the resulting bilayer membrane and polymeric nanostructure properties for a specific application by combining the right copolymer and detergent type ${ }^{13}$.

107 In the presented work, we investigated the detailed effects of the three detergents on a poly(ethylene glycol)-block-poly( $\varepsilon$-caprolactone) (PEG-PCL) based polymersome system. PEG-PCL consists of a non-toxic PEG section and an in-vivo biodegradable PCL part ${ }^{40-42}$. 110 They can be easily synthesized in large scale, with the use of non-toxic catalysts such as 
111 calcium ${ }^{43}$ or enzymes ${ }^{44}$, and self-assembled structures can be prepared via scalable methods,

112 such as direct hydration ${ }^{2,40}$. This makes PEG-PCL based systems attractive for industrial

113 applications such as drug delivery ${ }^{40,45}$. Furthermore, PEG-PCL products are already approved

114 as drug delivery systems by health care authorities, such as the U.S. Food and Drug

115 Administration (FDA) ${ }^{2,46}$. Multiple studies have investigated PEG-PCL systems for

116 conjugation with proteins (e.g. glycoproteins or antibodies), cell binding (targeting studies),

117 and cell viability ${ }^{40,47-49}$, however there is no study focusing on the PEG-PCL bilayer

118 solubilization. To the best of our knowledge, this is the first study to investigate the detergent-

119 induced vesicle solubilization of a polymersome system that combines OD analysis, DLS,

120 tunable resistive pulse sensing (TRPS), and cryoTEM. Due to the joint application of the

121 above-mentioned analytical methods, the effect of solubilization was characterized, not only

122 qualitatively (by optical density and average particle size), but also quantitatively (by TRPS

123 measurements providing particle size distribution and particle concentrations in the solution).

124 Further understanding of the process has been provided by the precise morphology analysis

125 using cryoTEM. This study explains, in detail, the mechanism of solubilization of PEG-PCL

126 polymersomes induced by three different detergents.

127 


\section{Experimental Section}

\section{Materials}

130 The three detergents used - N-Octyl- $\beta$-D-Glucopyranoside (OG), Lauryldimethylamine N131 oxide (LDAO) and Triton X-100 (TX-100) - in the study are commonly employed in bilayer

132 membrane research for solubilization, or the extraction and reconstitution of transmembrane 133 proteins ${ }^{23,27,50,51}$. The detergents have different chemical structures, MWs, and critical micelle 134 concentrations (CMC) in pure $\mathrm{H}_{2} \mathrm{O}$ and those are presented in Figure 1.

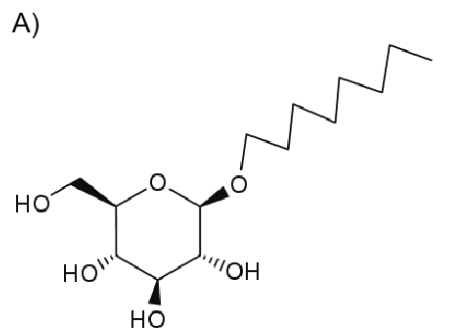

B)

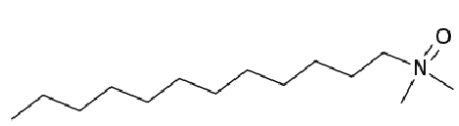

C)

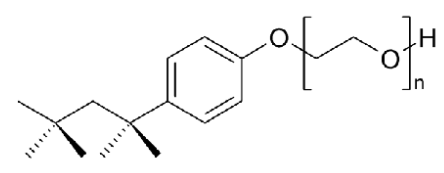

135

136

Figure 1. Chemical structures of the detergents used in the study, A)-N-Octyl- $\beta$-D-Glucopyranoside $(M W=$ $292 \mathrm{~g} / \mathrm{mol}, C M C \approx 20.0 \mathrm{mM}) ; B)$ - Lauryldimethylamine $N$-oxide $(M W=229 \mathrm{~g} / \mathrm{mol}, \mathrm{CMC} \approx 2.0 \mathrm{mM}) ; C)-T X$ $100(n=10)(M W=625 \mathrm{~g} / \mathrm{mol} \mathrm{CMC} \approx 0.24 \mathrm{mM})$.

N-Lauryldimethylamine N-oxide (30 \% aqueous solution) was obtained from Sigma Aldrich,

140 Denmark and used as received. N-Octyl- $\beta$-D-Glucopyranoside $(\geq 99 \%)$ was obtained from

141 Anatrace, USA and used as 30\% aqueous solution. TX-100 ( $\geq 99.8 \%)$ was obtained from

142 Sigma Aldrich, Denmark and used as 20\% aqueous solution. Phosphate buffered saline (PBS)

143 was prepared by dissolving the salts $\left(8 \mathrm{mg} / \mathrm{mL} \mathrm{NaCl}, 0.2 \mathrm{mg} / \mathrm{mL} \mathrm{KCl}, 1.44 \mathrm{mg} / \mathrm{mL} \mathrm{Na}_{2} \mathrm{HPO}_{4}\right.$,

$1440.24 \mathrm{~g} \mathrm{KH}_{2} \mathrm{PO}_{4}$ ) in Milli-Q water, $\mathrm{pH}$ was adjusted to 7.4 with $\mathrm{HCl}$. All chemicals for

145 preparation of PBS were analytical grade and were obtained from Merck KGaA, Germany.

146 Poly(ethylene glycol) methyl ether (Mn 550) (PEGME) was obtained from Merck KGaA,

147 Germany. Poly(ethylene glycol) 45 -block-poly(e-caprolactone) 44 (PEG45-PCL44) (PDI 1.2) 
was purchased from Advanced Polymer Materials, Canada. Proton nuclear magnetic resonance

149 (H-NMR), size-exclusion liquid chromatography (SEC) analyses for the diblock copolymer are presented in the Supporting Info in the Figures S1 and S2, respectively The results of differential scanning calorimetry (DSC) are presented in the Figures S3 and S4.

\section{Preparation of Polymersomes}

Polymersomes were prepared via direct hydration as previously reported in Sui et al, in PBS $(\mathrm{pH} 7.4,136 \mathrm{mM} \mathrm{NaCl}, 2.6 \mathrm{mM} \mathrm{KCl})^{40}$. In brief, $1 \mathrm{~g}$ of PEG-PCL was mixed with $10 \mathrm{~g}$ of PEGME, to promote the hydration of copolymer, as PEGME is both soluble in the polymer as well as in water. The mixture was heated to $60^{\circ} \mathrm{C}$ and stirred at $300 \mathrm{rpm}$ for 30 minutes. Subsequently, the temperature was lowered to $40^{\circ} \mathrm{C}$, and $100 \mathrm{~mL}$ of PBS buffer was added. The obtained solution was stored at room temperature and filtered through a $0.2 \mu \mathrm{m}$ polyethersulfone (PES) filter (Sarstedt, Germany) prior to use.

Characterization of Polymersomes and the Solubilization Process

OD measurements were made with a Varioskan ${ }^{\mathrm{TM}}$ microplate reader (Thermo Fischer Scientific, MA, USA) to determine the vesicle-solubilizing concentrations for each detergent. To perform the titration experiment, $200 \mathrm{uL}$ of filtered polymersome solution was mixed with detergent to obtain the desired concentration in the well of a polystyrene flat-bottom, clear microplate (Greiner Bio-One, Austria). Kinetic OD measurements at a wavelength of $400 \mathrm{~nm}$ were made at specified time points at $20^{\circ} \mathrm{C}$. All samples were prepared in triplicate. We observed no further changes in OD after 90 minutes of detergent incubation and therefore chose 2 hours for the detergent incubation time in the analyzed samples. 
175 To prepare the samples for DLS measurements, filtered polymersome solution was mixed with 176 detergents to reach the desired concentrations and was stirred for 2 hours at $750 \mathrm{rpm}$ at room 177 temperature. Average hydrodynamic diameter (Z-Avg) and polydispersity index (PDI) 178 measurements were made by a DLS instrument, the Zetasizer Nano (Malvern, UK). All measurements were made in batch mode at $20^{\circ} \mathrm{C}$ using poly(methyl methacrylate) (PMMA) cuvettes (Sarstedt, Germany). The DLS measured samples were further analyzed by cryoTEM visualization and TRPS measurements.

182

Samples for visualization were vitrified on a glow-discharged lacey formvar film enforced by silicon monoxide coating and supported by a copper mesh grid (Ted Pella Inc., USA). The samples were vitrified in liquid ethane with use of Vitrobot ${ }^{\mathrm{TM}}$ Mark IV (FEI, USA) and subsequently mounted in a Gatan cryoholder (FEI, USA). The images were acquired in cryogenic mode using a Tecnai G2 20 TWIN 200 kV TEM equipped with a FEI High-Sensitive $4 \mathrm{k}$ x $4 \mathrm{k}$ Eagle camera. Sensing

193 Virgin sample and three samples corresponding to each stage of solubilization, based on the results from OD, DLS, and cryoTEM analyses, for each of the detergents were chosen for TRPS analysis, , Size distribution and particle concentrations measurement were analysed with a TRPS qNano Gold system (Izon Science, New Zealand), equipped with a NP150

197 polyurethane nanopore (Izon Science, New Zealand) and by following the standard protocol 
198 recommended by the manufacturer ${ }^{52}$. The analytical window for TRPS measurements was 199 optimized for the particles with diameter between $50 \mathrm{~nm}$ and $550 \mathrm{~nm}$. To perform the TRPS

200 measurements, the samples were diluted 50 times with PBS buffer and analyzed under the 201 voltage of $0.96 \mathrm{~V}$ and a pressure of 13 millibar. Data analysis was performed using the data 202 capture and analysis software, Izon Control Suite V3.4 (Izon Science, New Zealand).

204 Results \& Discussion

\section{Characterization of Polymersome Solution}

206 The polymersome solution, without detergent addition, was analyzed with DLS, cryoTEM, 207 and TRPS as a standard for comparison to solutions with the three chosen detergents 208 throughout the rest of this study. The results of the DLS measurements of the polymersome solution before and after filtration through a $0.2 \mu \mathrm{m}$ polyethersulfone (PES) filter are listed in

Table 1. The cryoTEM images of the same solutions before and after filtration are shown in

$211 \quad$ Figure 2.

212 Table 1. Dynamic light scattering results of unfiltered and filtered (0.2 $\mu \mathrm{m}$ PES) PEG-PCL solution, presenting the PDI and hydrodynamic radiuses $\left(D_{h}\right)$ of the two particle populations measured.

\begin{tabular}{ccccc}
\hline & & & Peak 1 & Peak 2 \\
& PDI & Z-Avg & $\mathrm{D}_{\mathrm{h}}(\mathrm{nm}) /$ & $\mathrm{D}_{\mathrm{h}}(\mathrm{nm}) /$ \\
& & & Intensity $(\%)$ & Intensity (\%) \\
\hline Unfiltered & $0.45 \pm 0.02$ & $196 \pm 2 \mathrm{~nm}$ & $285 \pm 220 \mathrm{~nm} / 92 \%$ & $3200 \pm 1140 \mathrm{~nm} / 8 \%$ \\
Filtered via 0.2 & & & & \\
$\mu$ m PES & $0.25 \pm 0.01$ & $160 \pm 2 \mathrm{~nm}$ & $192 \pm 60 \mathrm{~nm} / 79 \%$ & $63 \pm 15 \mathrm{~nm} / 21 \%$ \\
\hline
\end{tabular}



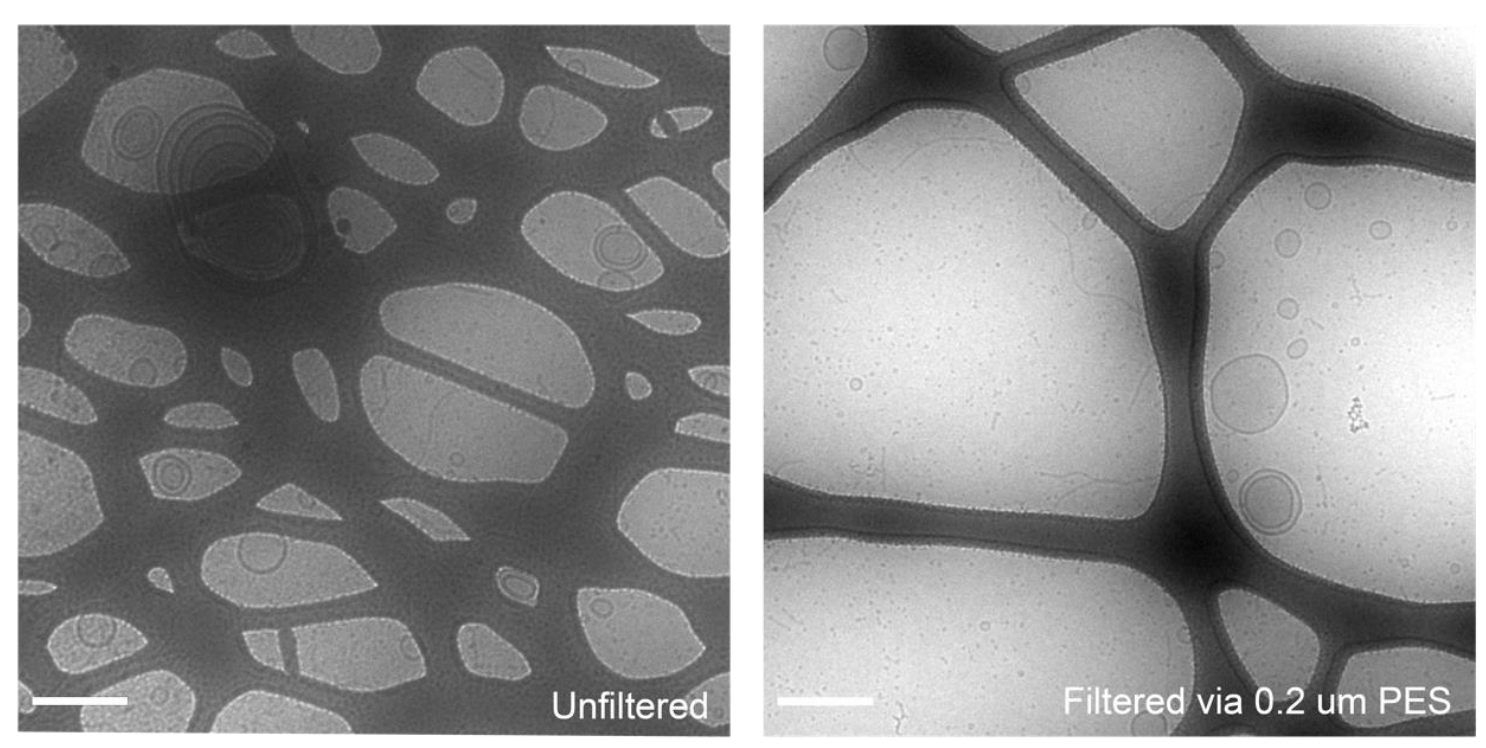

216 Figure 2. CryoTEM micrographs of unfiltered PEG-PCL polymersome solution (left) and filtered solution via

$2170.2 \mu \mathrm{m}$ PES filter (right), scale bar: $500 \mathrm{~nm}$.

219 CryoTEM visualization revealed that the unfiltered PEG-PCL polymersome solution consisted 220 of vesicles with a membrane thickness varying between 15-20 nm (majority unilamellar, 221 though some multilamellar vesicles were present). Additionally, the samples contained single micelles, rod-like micelles, and micrometer-sized multilamellar vesicles. Filtration removes the latter, however, rod-like micelles are still present in the filtered solution, together with submicron vesicles and single micelles. Likewise, the PDI of the filtered solution was 0.25 and the Z-Avg was $160 \mathrm{~nm}$, compared to a PDI of 0.45 and Z-Avg of $196 \mathrm{~nm}$ for the unfiltered sample. Through TRPS measurements, the concentration of the particles in the filtered PEG-PCL solution was measured to be in the range of $2 \mathrm{E}+13$ particles $/ \mathrm{mL}$, with a mean physical diameter of $115 \mathrm{~nm}$. A histogram of the particle distribution for the filtered solution is presented in Figure 3. Due to pore blockage from the presence of the micrometer-sized vesicles in the unfiltered PEG-PCL polymersome sample, it was not possible to measure particle distribution with TRPS. Throughout the rest of the article we refer to filtered PEG-PCL polymersome solution as the virgin sample. 
A)

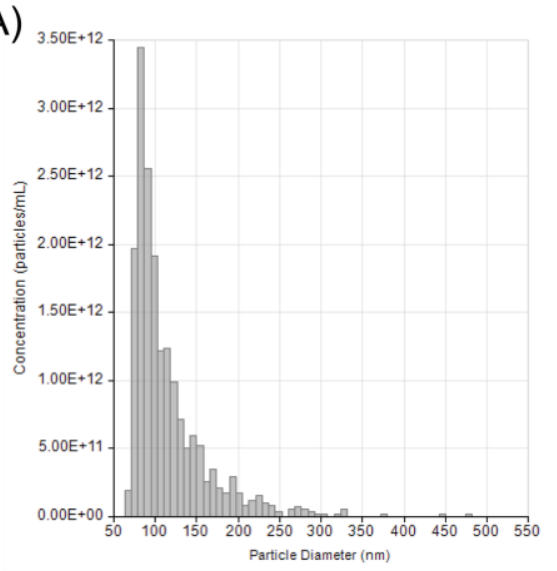

C)

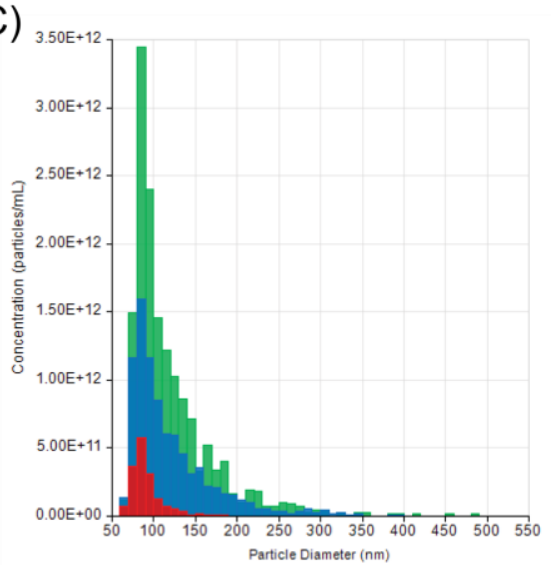

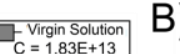

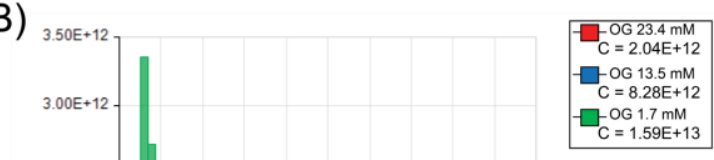

$\mathrm{C}=1.59 \mathrm{E}+13$
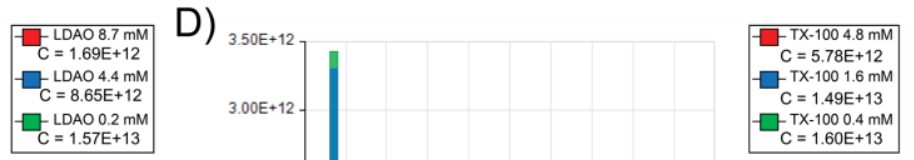

Figure 3. Particle size distribution histograms obtained from TRPS measurements: A) Starting material of the

B) Solutions with N-Octyl- $\beta$-D-Glucopyranoside (OG);

C) Solutions with

Lauryldimethylamine N-oxide (LDAO); D) Solutions with Triton X-100 (TX-100). The particle concentration drops as the detergent concentration is increased. TRPS has a limited resolution window and for the chosen settings particles $\leq 50 \mathrm{~nm}$ in diameter were not detectable.

\section{Three Stage Solubilization of PEG-PCL Polymersomes in Mixtures with}

\section{Detergents}

241 OG is a glucopyranoside and one of the most commonly applied nonionic detergent used for the solubilization of integral membrane proteins and their reconstitution into proteoliposomes,

243 due to its high CMC value and non-denaturating properties ${ }^{23,50,51,53,54}$. LDAO is a zwitterionic

244 amine oxide-based detergent with a C12 alkyl tail. It is widely used for solubilization of

245 bacterial membranes for the isolation of integral membrane proteins ${ }^{53-56}$. TX-100 is a nonionic

246 detergent often used for transmembrane protein reconstitution and it is known to penetrate the 
247 lipid membrane at the onset of solubilization without affecting the membrane bilayer structure

24831,39 . The selected detergents were chosen based on their frequent use in membrane protein 249 solubilization and reconstitution studies. OD measurements of the PEG-PCL polymersome 250 solutions with titrated detergents are presented in Figure 4. 

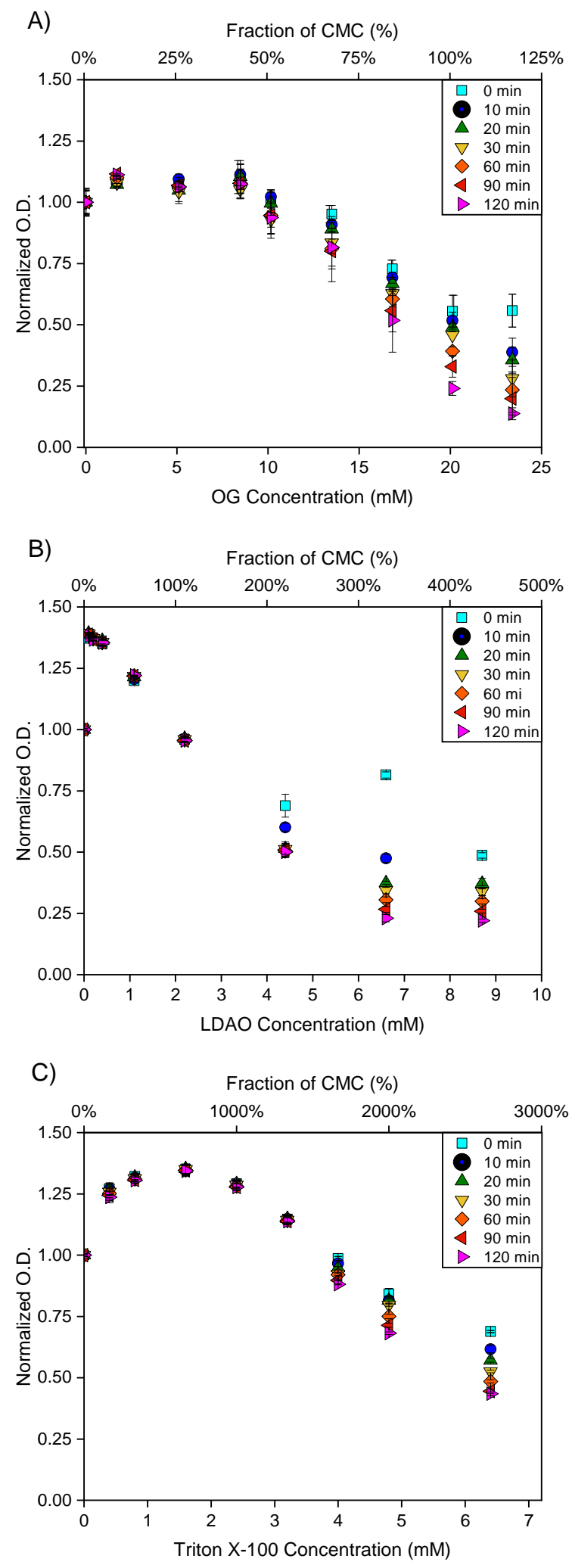

253 Figure 4. Results of the optical density (O.D.) measurements of the PEG-PCL polymersome upon introduction of

254 the detergents: A) N-Octyl- $\beta$-D-Glucopyranoside (OG); B) Lauryldimethylamine N-oxide (LDAO); C) Triton X-

255100 (TX-100). Concentrations are provided in $\mathrm{mM}$ as well as fractions of the critical micelle concentration

$256(C M C)$ 
257 The OD measurements were obtained to define the detergent concentrations at which the transition between the solubilization stages of PEG-PCL polymersomes occur for each detergent ${ }^{21}$. As show in in Figure 4A, at low concentrations of $\mathrm{OG}(1.7 \mathrm{mM}-8.5 \mathrm{mM})$ the normalized OD increased by 0.1 (for 120 minutes contact time). In contrast, upon introduction of LDAO and TX-100, normalized OD increased by 0.4 and 0.3 (see Figure 4B and 4C), respectively. The increase in turbidity for all of the investigated samples upon exposure to low detergent concentrations can be explained by the the increase of the vesicle diameter. This is in alignment with the first stage of bilayer solubilization. At the low concentrations of detergents, so-called subsolubilizing concentrations, an increase of the vesicle diameter occurs due to the penetration of the detergent molecules into the bilayer $25,28,57$. The subsequent observed drop in OD at increasing detergent concentrations (starting from $10.2 \mathrm{mM}, 1.1 \mathrm{mM}$, and $2.4 \mathrm{mM}$, for OG, LDAO, and TX-100, respectively) indicates initiation of the second stage of solubilization, where disintegration of the vesicles occurs due to their bilayer becoming saturated with detergent molecules. Full solubilization (stage 3) occured at $23.4 \mathrm{mM}$ for OG, 8.7 $\mathrm{mM}$ for LDAO, and $6.4 \mathrm{mM}$ for TX-100, when the normalized OD reached $0.13,0.22$, and 0.43 for OG, LDAO and TX-100 respectively. This observed drop in OD is related to the third stage of solubilization - formation of smaller single micelles with higher detergent-tocopolymer ratio. The limited drop in OD for TX-100 compared to OG and LDAO can be linked to the higher MW of TX-100 and incomplete bilayer penetration by the detergent ${ }^{21}$. Nonetheless, TX-100 solutions are known to have increased turbidity in comparison to LDAO and $\mathrm{OG}$, due to its lower cloud point in aqueous solution ${ }^{9}$. Moreover, Figure 4 shows that between the second and third stage of solubilization, OD measurements are more time dependent for all detergents, since disintegration of the vesicles is a kinetic process. 
282 After determining the changes in OD of the polymersome solutions with the three detergents

283 DLS measurements were made as a first step to explain the morphological changes happening

284 upon detergent titration. Namely, the average diameter of particles (Z-Avg) and the 285 polydispersity index (PDI) were measured. The results of the DLS measurements for the samples with different OG concentrations are presented in Figure 5A.
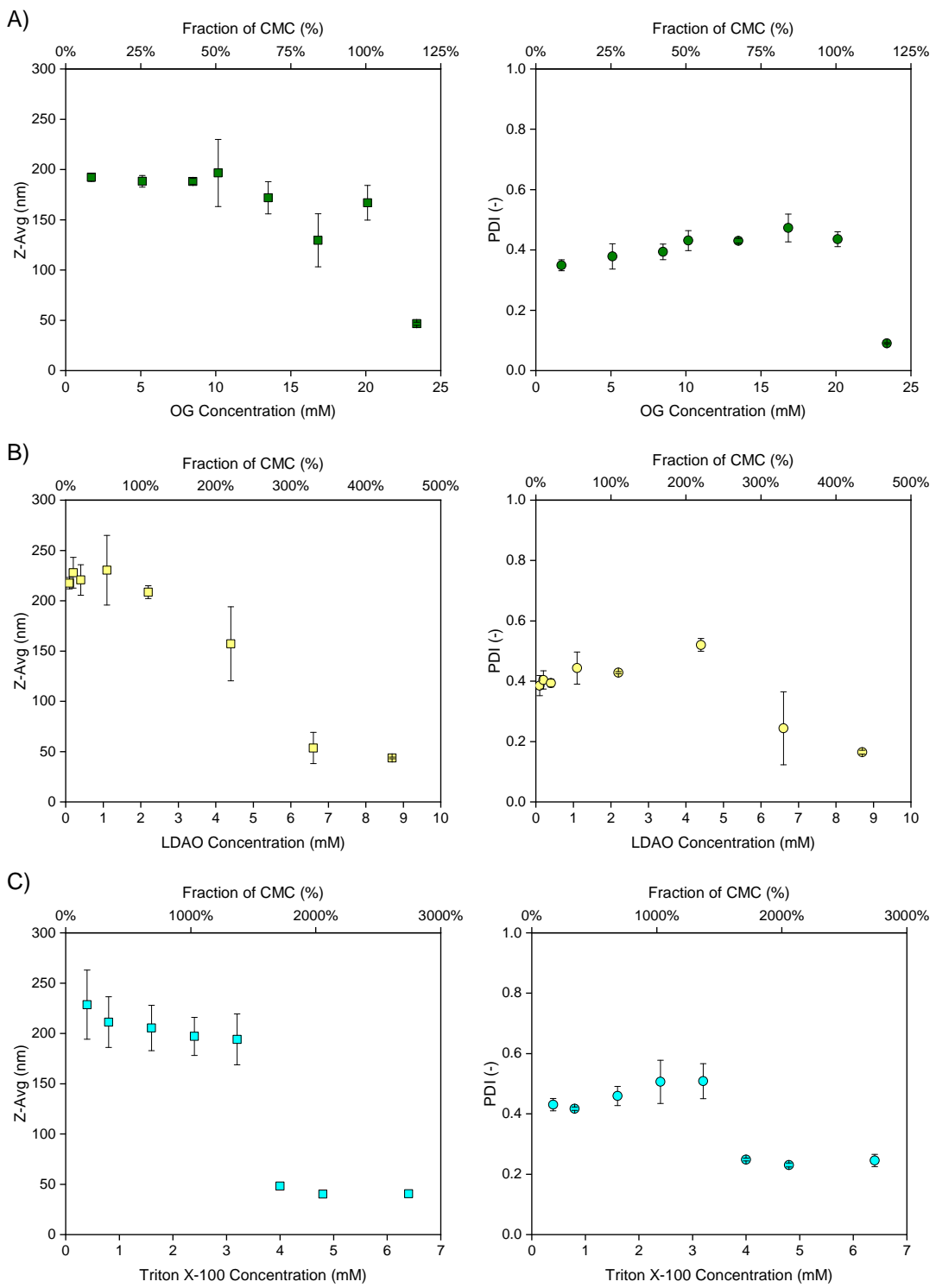

Figure 5. DLS measured average hydrodynamic diameter (Z-Avg) and polydispersity index (PDI) of particles upon introduction of the detergents: A) N-Octyl- $\beta$-D-Glucopyranoside (OG); B) Lauryldimethylamine $N$-oxide (LDAO); C) Triton X-100 (TX-100). The Z-Avg and PDI drops sharply when the detergent concentration capable of solubilizing the majority of the vesicles is reached. 
292 At concentrations of OG between $1.7 \mathrm{mM}$ to $13.5 \mathrm{mM}$, the Z-Avg remains unchanged at roughly $200 \mathrm{~nm}$, indicating that the vesicles were stable within this range. However, cryoTEM micrographs (presented in Figure 6) show that from $5.1 \mathrm{mM} \mathrm{OG}$, the number of rod-like micelles and single micelles was significantly higher than for the virgin sample. Interestingly, at a concentration of $5.1 \mathrm{mM}$ OG the presence of rod-like micelles was the most prominent morphology, in comparison to the other samples containing OG. This explains the increased OD of the solutions (see Figure 4A), as the enlarged vesicles with detergent-saturated bilayers are present with single micelles and rod-like micelles in the sample ${ }^{19,21}$. The significant increase of the population of rod-like micelles is barely detectable by DLS, as Z-Avg remain unchanged and PDI only slightly increases, due to the large vesicles scattering light with a higher intensity than the smaller particles present in the solution. At $13.5 \mathrm{mM}$ OG, a detergent concentration in the middle of the second stage of solubilization, the total particle concentration measured by TRPS dropped from $2 \mathrm{E}+13$ particles / $\mathrm{mL}$ to $8 \mathrm{E}+12$ particles / $\mathrm{mL}$ (for the particles above $50 \mathrm{~nm}$ ). Moreover, the number of the particles in the range of $100-200 \mathrm{~nm}$ in physical diameter, corresponding to vesicles, dropped by half (see Figure 3A), from $3 \mathrm{E}+12$ particles / $\mathrm{mL}$ to $1.5 \mathrm{E}+12$ particles / $\mathrm{mL}$.

After reaching concentrations of $20.1 \mathrm{mM} \mathrm{OG}$, Z-Avg drops to $167 \pm 17 \mathrm{~nm}$ and PDI increases to $0.43 \pm 0.03$, indicating an increased number of single micelles in the solution and a decreased number of vesicles. As shown in cryoTEM micrographs (Figure 6), mostly single-micelles and rod-like micelles were present in the solution, with a few vesicles visible with radiuses below $100 \mathrm{~nm}$. 
316 At concentrations reaching $23.4 \mathrm{mM} \mathrm{OG}$, the bilayer of the vesicles was completely

317 solubilized. The Z-Avg dropped to $50 \pm 2 \mathrm{~nm}$ and the PDI was reduced to $0.10 \pm 0.01$. This is

318 also confirmed by TRPS measurements, as the measured total particle concentration dropped

319 to $2.04 \mathrm{E}+12$ (see Figure $3 \mathrm{~A}$ ). No pore formation in the vesicle bilayer, typically observed for

320 liposomes ${ }^{21,25}$, was observed with cryoTEM at any of the OG concentrations.
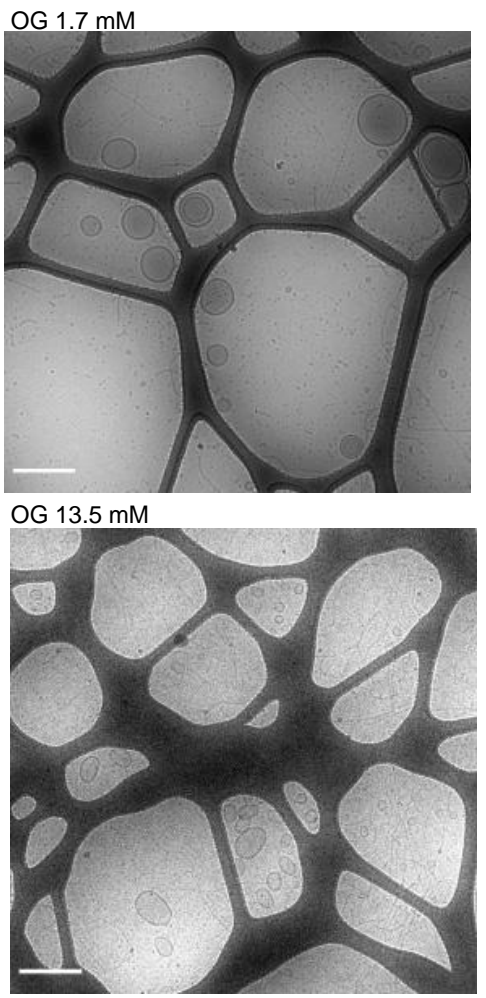

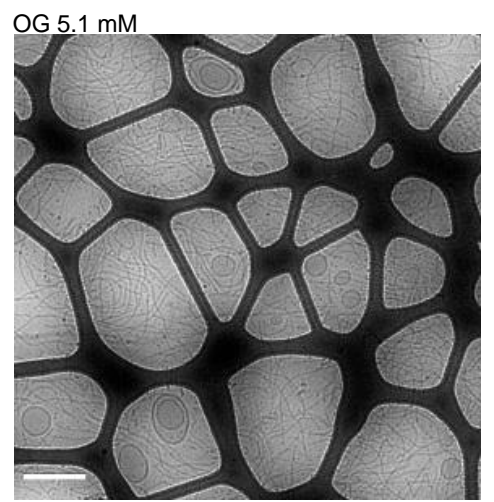

OG $20.1 \mathrm{mM}$

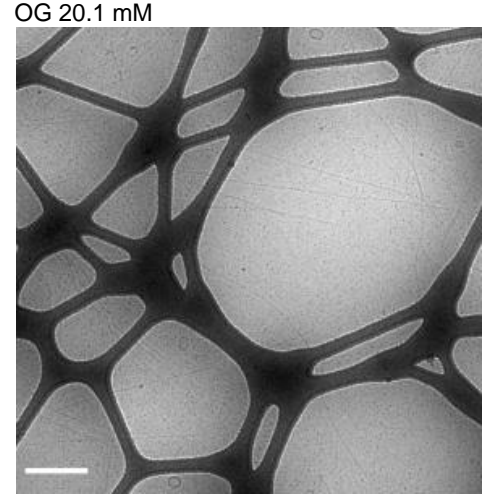

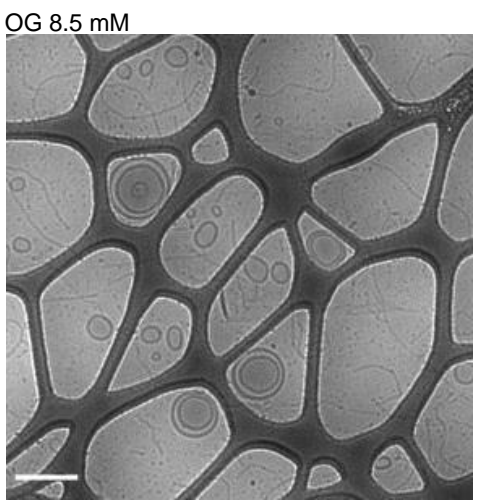

OG $23.4 \mathrm{mM}$

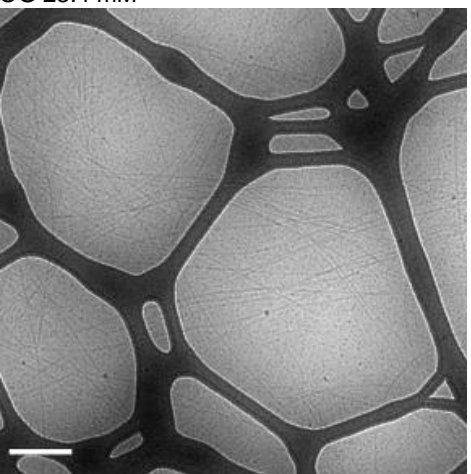

Figure 6. Cryogenic Transmission Electron Microscopy micrographs of vesicle samples with different concentrations of $\mathrm{N}$-Octyl- $\beta$-D-Glucopyranoside $O G$, scale bar: $500 \mathrm{~nm}$.

\section{Effect of Lauryldimethylamine N-oxide on Polymersome Morphology}

The Z-Avg and PDI of polymersome solutions exposed to increasing LDAO concentrations are presented in Figure 5B. At concentrations up to $2.2 \mathrm{mM}$ LDAO, the Z-Avg and PDI remained unaffected, averaging at sizes of $210-230 \mathrm{~nm}$ with a PDI of $0.40-0.44$. These numbers indicate stability of the polymersomes in the presence of the detergent as they show a slight 
330 increase in size, but are still similar to the results from the virgin solution (see Table 1 and

331 Figure 2). These changes also correlate to the increase in OD, up to concentrations of $1.1 \mathrm{mM}$

332 LDAO (see Figure 4B). The cryoTEM micrographs of the samples with $0.2 \mathrm{mM}$ and $1.1 \mathrm{mM}$

333 LDAO exhibit enlarged vesicles (Figure 7) confirming the DLS and OD readings.
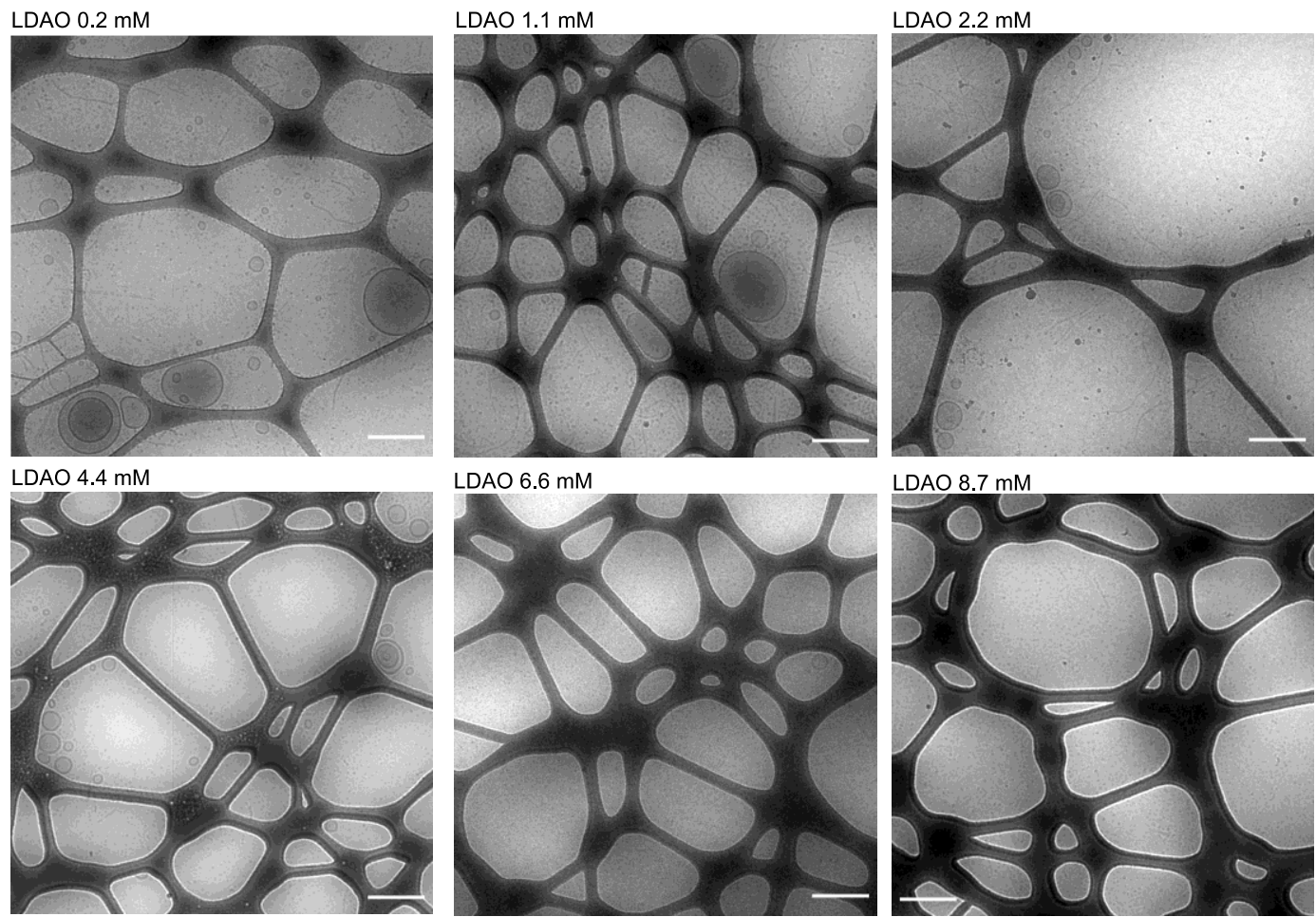

334

Figure 7. Cryogenic Transmission Electron Microscopy micrographs of vesicle samples with different concentrations of ) Lauryldimethylamine N-oxide (LDAO), scale bar: $500 \mathrm{~nm}$.

338 However, for the sample with 2.2 mM LDAO, the OD decreased in comparison to the samples with lower LDAO concentrations. This is due to the decreased vesicle concentration and size which is observable on the cryoTEM micrograph (Figure 7). The DLS measurement is not sensitive to these changes, as PDI and Z-Avg remain unchanged at LDAO concentrations up to $2.2 \mathrm{mM}$. 
344 At $4.4 \mathrm{mM}$ LDAO, the Z-Avg decreased sharply to $157 \pm 37 \mathrm{~nm}$ and PDI increased to $0.52 \pm$

345 0.02. Additionally, the error of the measurements was also increased at this concentration (see

346 Figure 5B). These results indicate that the average size of the particles decreased, while 347 differences in the particle populations became more prominent. The cryoTEM micrograph of 348 the sample with $4.4 \mathrm{mM}$ LDAO, shows the presence of predominantly unilamellar vesicles.

349 These vesicles were smaller in size in comparison to the polymersome samples with $0.2 \mathrm{mM}$ and $1.1 \mathrm{mM}$ LDAO (Figure 7). The size of the vesicles in the polymersomes sample with 4.4 mM LDAO was comparable to the sample containing 2.2 mM LDAO, however, the population of rod-like micelles was decreased. They were most likely solubilized to single micelles, which were present in the solution with the vesicles. These morphological findings correlate to the

354 OD measurements, as the polymersome sample with $4.4 \mathrm{mM}$ LDAO experienced a sharp drop in OD (see Figure 4B). The drop in concentration of vesicles at 4.4 mM LDAO was quantified with TRPS (see Figure 3B), as the total concentration of particles dropped from $2 \mathrm{E}+13$ particles $/ \mathrm{mL}$ in the virgin solution, to $8.65 \mathrm{E}+12$ particles / $\mathrm{mL}$. Furthermore, the concentration of particles between 100-200 $\mathrm{nm}$ was reduced by half, which is identical to the effect observed at $13.5 \mathrm{mM}$ of OG, which is the concentration where stage 3 of the solubilization process occurs (see Figure 3A).

In contrast to OG, the rod-like micelle morphology tends to decay at increased LDAO concentrations (above $4.4 \mathrm{mM}$ ), with most of the particles being single micelles. Even though the two detergents have similar MW - $229 \mathrm{~g} / \mathrm{mol}$ for LDAO and $292 \mathrm{~g} / \mathrm{mol}$ for OG, their critical micelle concentration is different. LDAO is characterized by a 10 -fold lower CMC value $(\sim 2$ $\mathrm{mM}$ in pure $\left.\mathrm{H}_{2} \mathrm{O}\right)$ compared to $\mathrm{OG}\left(\sim 20 \mathrm{mM}\right.$ in pure $\left.\mathrm{H}_{2} \mathrm{O}\right)$. Thus, LDAO molecules arrange into micelles at lower concentrations than OG, and in combination with PEG-PCLchains, are more prone to form single micelles than long rods, thereby solubilizing the bilayer at lower 
concentrations than OG. At $6.5 \mathrm{mM}$ LDAO the PDI dropped to $0.24 \pm 0.12$, and Z-Avg to 54

$370 \pm 16 \mathrm{~nm}$. While the error of the PDI readings was more pronounced, these DLS results

371 correlate with the observed drop in concentration of polymersomes and an increased

372 concentration of single micelles - also confirmed by cryoTEM imaging (Figure 7). Complete

373 solubilization was reached at $8.7 \mathrm{mM} \mathrm{LDAO}$, where the measured PDI was $0.16 \pm 0.01$ and

374 Z-Avg reached $44 \pm 1 \mathrm{~nm}$. CryoTEM confirmed that the sample mostly contained single

375 micelles and sub-200 nm length rod-like micelles, while the TRPS measurement showed a

376 reduction in total particle concentration to $1.69 \mathrm{E}+12$ particles / $\mathrm{mL}$. Similar to $\mathrm{OG},-$ no pore

377 formation was observed within the vesicle bilayer was observed on cryoTEM micrographs at

378 any point during the vesicle solubilization (see Figure 7).

379

380

\section{Effect of Triton X-100 on Polymersome Morphology}

381 The PDI and Z-Avg masured by DLS for polymersomes mixed with TX-100 are presented in

382 Figure 5C. TX-100 did not induce significant changes to the Z-Avg, at concentrations up to

$3833.2 \mathrm{mM}$ TX-100. However, the cryoTEM micrograph of the sample with $0.4 \mathrm{mM}$ TX-100

384 (presented in Figure 8), showed larger vesicles in comparison to the virgin solution (see Figure

385 2), which was also observed as an increase in the OD measurements (see Figure 4C). 


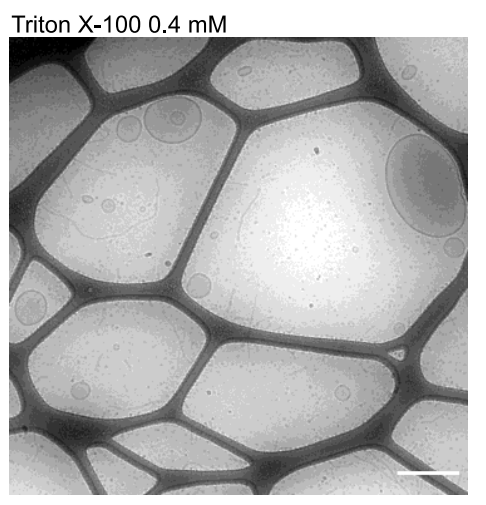

Triton X-100 $2.4 \mathrm{mM}$

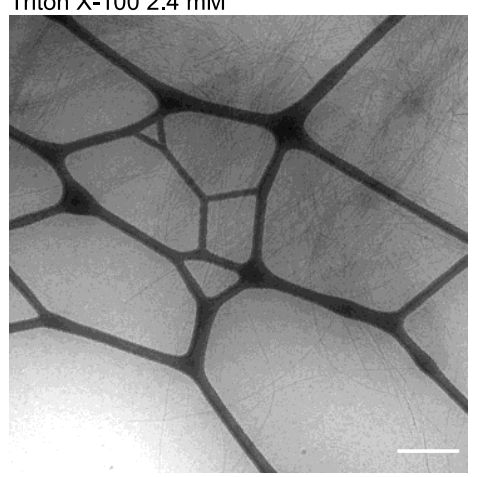

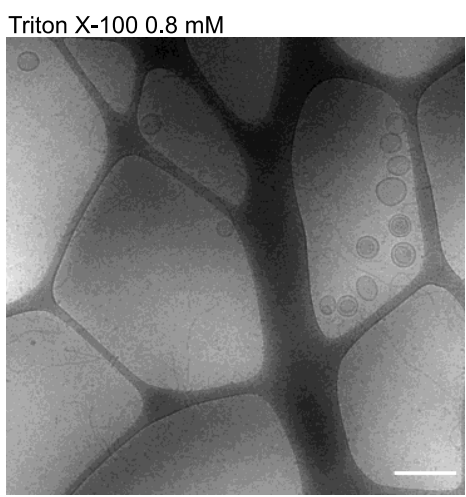

Triton X-100 4.0 mM

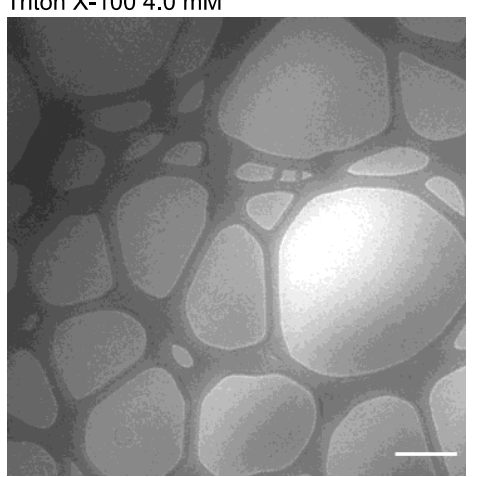

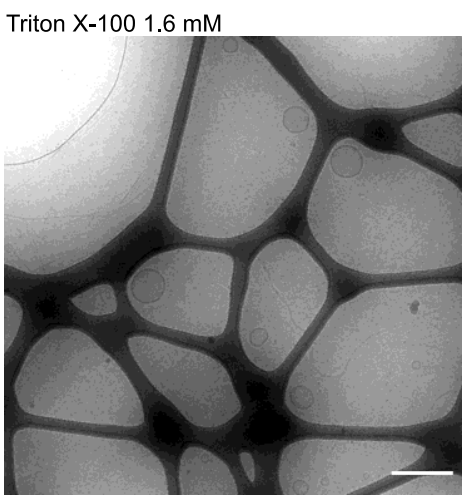

Triton X-100 4.8 mM

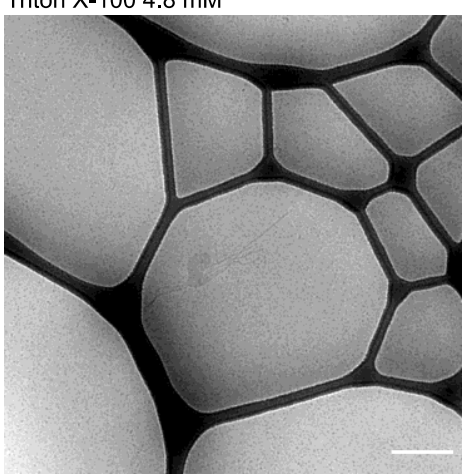

Figure 8. Cryogenic Transmission Electron Microscopy micrographs of vesicle samples with different concentrations of Triton X-100 (TX-100), scale bar: $500 \mathrm{~nm}$.

The PDI did increase at concentrations up to $3.2 \mathrm{mM}$ of TX-100. This relates to the morphological changes observed with cryoTEM. Upon the additionof TX-100, long rod-like micelles were formed with lengths exceeding $2 \mu \mathrm{m}$. Their population and lengths increased until a concentration of $4.0 \mathrm{mM}$ of TX-100 was reached, where most of the structures were solubilized into single micelles (see Figure 8). When the concentration reached 4.0 mM TX100 , it could be elucidated from DLS measurements that a complete vesicle solubilization took place, since the Z-Avg dropped to $48 \pm 1 \mathrm{~nm}$ and the PDI dropped to $0.25 \pm 0.02$. Some vesicles were still visible on the cryoTEM micrographs at $4.0 \mathrm{mM} \mathrm{TX}-100$, though their population was greatly reduced. While a futher increase in the detergent concentration resulted in a continued decrease of OD (see Figure 4C), the Z-Avg and PDI remained constant. A PDI below 0.2 was not reached even at the highest tested concentration of $6.4 \mathrm{mM}$ TX-100, as in 
the case of OG and LDAO, when complete solubilization was achieved. This could indicate that a small portion of the insolubilized vesicles was still present. Nevertheless, cryoTEM micrographs of the $4.8 \mathrm{mM}$ TX-100 sample, revealed unusual aggregates with a morphology between large micelles and rod-like micelles (see Figure 8). The results of TRPS measurements (presented in Figure 3D) showed that the total particle concentration was 1.60E+13 particles / $\mathrm{mL}, 1.49 \mathrm{E}+13$ particles $/ \mathrm{mL}$ and $6.78 \mathrm{E}+12$ particles $/ \mathrm{mL}$ for $0.4 \mathrm{mM}, 1.6 \mathrm{mM}$, and $4.8 \mathrm{mM}$ TX-100, respectively. A sharp decrease in the concentration of particles in size range of 100$200 \mathrm{~nm}$, in comparison to the virgin solution, was recorded only for the sample with $4.8 \mathrm{mM}$ TX-100. Nevertheless, the particle concentrations did not drop to the levels observed for the samples with OG and LDAO (Figure 3B and 3C). The concentration of $100 \mathrm{~nm}$ particles at 4.8 mM TX-100 was twice as high as the highest concentrations of $\mathrm{OG}(23.4 \mathrm{mM})$ and LDAO (8.7 $\mathrm{mM}$ ) with $1 \mathrm{E}+12$ particles $/ \mathrm{mL}$ for $\mathrm{TX}-100$, in comparison to $5 \mathrm{E}+11$ particles $/ \mathrm{mL}$ for both OG and LDAO. We speculate that this discrepancy in particle concentration is due to the presence of the amorphous aggregates formed when TX-100 was used for the polymersome solubilization. The phenomenon of formation of amorphous aggregates can be explained by the significantly higher MW of TX-100 (615 g/mol) in comparison to OG and LDAO, and the difference in the structure of the hydrophilic and hydrophobic moieties of the detergents. TX100 consists of a long hydrophilic chain of PEG and a hydrophobic alkylphenyl group, in comparison to LDAO and OG, which both have hydrophobic chains and a hydrophilic groups. LDAO has the smallest hydrophilic region composed of amine oxide and OG has a large glucose headgroup (see Figure 1). TX-100 has the lowest CMC of the three tested detergents, however it was found to be the least effective, solubilizing the bilayer at CMC fractions reaching $2000 \%$ even though TX-100 has previously been described, in early work on

423 liposome solubilization, to reside within the group of 'fast-solubilizing' detergents ${ }^{21,26,58}$. TX424100 instead slowly and partially solubilizes the bilayer, which leads to the formation of larger 
aggregates and mixed micelles. The breakdown of the bilayer should result in the partial destabilization of the vesicles and consequently to the leakage of vesicles, but no vesicles with an open bilayer were observed with cryoTEM.

\section{Comparison of the Observed Solubilization Process to the Literature}

The three stages of solubilization were defined and studied for PEG-PCL polymersomes exposed to increasing concentrations of the three investigated detergents until complete solubilization and breakdown of the vesicles was confirmed. Across the whole studied concentration spectras of the investigated detergents, opened pores were not observed within the vesicle bilayer. The formation of pores was expected at the solubilizing concentrations since such phenomena is known to occur in liposomes and is considered a prerequisite for the vesicle solubilization $^{21,25}$. It can be speculated that the absence of pore formation is a result of a significant mismatch in the detergent length in comparison to the diblock chain. Even for the largest detergent molecule in this study - TX-100 - the mass of the PEG45-PCL44 chain (average MW $=7000 \mathrm{~g} / \mathrm{mol}$ ) is more than 10 times larger. In comparison, for commonly used vesicle-forming phospholipids, MW ranges between 700 and $800 \mathrm{~g} / \mathrm{mol}{ }^{59}$, which is significantly closer to the MW of the detergents. Additionally, polymers have certain characteristics that are absent in the lipid constituents. Polymers are not perfectly pure systems, even when the PDI is low. The block copolymer used in this study was characterized with a PDI of 1.2. Nevertheless, in contrast to pure lipid mixtures, a polymer mixture will always consists of polymer chains with a variety of block lengths ${ }^{60}$. These polymers with non-uniform chain lengths build the vesicle bilayer, and due to the membrane liquidity and lateral diffusion, they will be able to reshuffle within the layer.Thus, enabling chain configurations to alter within the bilayer and modifying the packing of the chains. In fact, molecular dynamics modelling has indicated that block copolymer membranes are capable of adjusting the 
thickness of the bilayer when facing membrane constituents with a hydrophobic mismatch. As

451

452

453

454

455

456

457

458

459

460

461

462

463

464

465

466

467

468

469

470

471

472

473

474 a result, polymer chains not only move within the bilayer, but they are also able to compress in the vicinity of the molecule causing the hydrophobic mismatch - such as membrane proteins 7,8,61,62 . Similar behavior can be expected when detergents, with much shorter hydrophobic chains than the polymer molecules, are incorporated into the bilayer.

Due to the MW of the PEG-PCL diblock copolymer, a fully-extended, hydrophilic PEG block will always be longer than a hydrophilic head of a lipid molecule, and the hydrophilic constituent of the detergent. Due to the significantly longer hydrophilic region of the detergent, it should be more difficult for the detergent to penetrate through the hydrophilic moiety of the amphiphilic polymer in comparison to its lipid counterpart ${ }^{1,8,11,19,63}$. Thus, a higher stability of the bilayer towards detergent attack would be expected. Nevertheless, in this work we have found that the concentrations required to solubilize PEG-PCL based polymersomes can be significantly lower than those reported for liposomes, such as a reported concentration of 80 $\mathrm{mM}$ OG required to solubilize $15 \mathrm{mg} / \mathrm{mL}$ of egg lecithin vesicles ${ }^{64}$, or egg sphingomyelin $(\mathrm{SM}) /$ cholesterol vesicles that were reported to withstand concentrations as high as $5 \mathrm{mM}$ of TX-100 ${ }^{24} .6 .4 \mathrm{mM}$ was the highest TX-100 concentration used in this study, which is less than a half of the concentration reported by Nallani et al. to solubilize $10 \mathrm{mg} / \mathrm{mL}$ of eggphosphatidylcholine (PC) lipid vesicles (16 mM TX-100), where the analysis was based on DLS and OD measurements ${ }^{65}$. The bilayer stability towards detergent is very material dependent ${ }^{22}$, as other liposomal formulations have been reported to be completely solubilized at concentrations as low as $0.3 \mathrm{mM}$ or $0.4 \mathrm{mM}$ TX-100, for SM and 1-palmitoyl-2-oleoyl-snglycero-3-phosphocholine based systems respectively ${ }^{24}$. The analyzed PEG-PCL system is more prone to a detergent attack than previously described polymersomes of PMOXA-PDMS $(5 \mathrm{mg} / \mathrm{mL})$, which were reported to fully withstand concentrations of $16 \mathrm{mM}$ of TX-100 ${ }^{31}$. 
475 Higher sensitivity to the detergent presence, may be caused by the less flexible hydrophobic 476 building block of the copolymer (PCL) in comparison to PDMS ${ }^{66}$. Flexible PDMS chains may

477 be expected to accommodate detergent molecules easier than stiffer PCL, resulting in higher 478 stability of the bilayer towards detergent attack ${ }^{8}$. Obviously, concentration of the particles will 479 be an essential factor affecting the detergent concentration at which solubilization occurs. The 480 mentioned studies do not include particle concentration measurements, thus the quantitative comparison of the results is limited.

482

\section{Summary and Conclusions}

484 This work presents the first analysis of detergents' effect on PEG-PCL based polymersomes. 485 It is the first thorough analysis combining OD and DLS measurements with detailed qualitative cryoTEM analysis and quantitative TRPS particle concentration measurements. We have demonstrated the effect of an increasing concentration of three detergents: OG, LDAO, and TX-100 on PEG-PCL polymersomes. The titration of these detergents into the polymersome solutions was carried out to the point at which no polymersomes were observed on cryoTEM micrographs. It has been found that despite the higher MW of polymers in comparison to lipid molecules (thus expected higher stability of polymersomes in general), significantly lower concentrations of detergents can disrupt the vesicular bilayer of PEG-PCL, than was previously reported for liposomes. The solubilization mechanism of polymersomes is comparable to that

494 of liposomes, however the expected pore formation within the bilayer was not observed for the 495 PEG-PCL polymersomes at any stage of the solubilization with the tested detergents. The behavior of the solubilization also differs depending on the detergent used. Even though LDAO and OG have ten and one hundred fold higher CMC than TX-100, respectively, it was shown 
499 fractions. This effect is caused by the significantly higher MW and difference in structural 500 properties of TX-100 in comparison to LDAO and OG.

501

\section{Acknowledgements}

503 This work was a part of the Industrial PhD project Development of Next Generation of 504 Aquaporin Inside ${ }^{T M}$ biomimetic membranes, co-founded by Innovation Fund Denmark and Aquaporin A/S. The authors would like to acknowledge the staff of the Core Facility for Integrated Microscopy at University of Copenhagen - Klaus Qvortrup, Tillmann Pape and Michael Johnson, and thank them for help and support in obtaining cryogenic transmission electron microscopy images of the samples.

\section{Supporting Information}

511 Figure S1. H-NMR spectrum of PEG-PCL diblock and chemical structure.

512 Figure S2. Size-exclusion liquid chromatography chromatogram of the PEG-PCL diblock.

513 Figure S3. Differential scanning calorimetry curve of PEG-PCL diblock.

514 Figure S4. Differential scanning calorimetry curve, representing $\mathrm{T}_{\mathrm{g}}$ region of the PEG-PCL 515 diblock.

\section{References}

518 (1) Palivan, C. G.; Goers, R.; Najer, A.; Zhang, X.; Car, A.; Meier, W. Bioinspired Polymer Vesicles and Membranes for Biological and Medical Applications. Chem. Soc. Rev. 2016, 45, 377-411. https://doi.org/10.1039/C5CS00569H.

(2) Grossen, P.; Witzigmann, D.; Sieber, S.; Huwyler, J. PEG-PCL-Based Nanomedicines: 260 (May), 46-60. https://doi.org/10.1016/j.jconrel.2017.05.028. 
524 (3) Hélix Nielsen, C. Biomimetic Membranes for Sensor and Separation Applications. Anal. Bioanal. Chem. 2009, 395 (3), 697-718. https://doi.org/10.1007/s00216-0092960-0.

(4) Kowal, J.; Zhang, X.; Dinu, I. A.; Palivan, C. G.; Meier, W. Planar Biomimetic Membranes Based on Amphiphilic Block Copolymers. ACS Macro Lett. 2014, 3 (1), 59-63. https://doi.org/10.1021/mz400590c.

(5) Gunkel-Grabole, G.; Sigg, S.; Lomora, M.; Lörcher, S.; Palivan, C. G.; Meier, W. P. Polymeric 3D Nano-Architectures for Transport and Delivery of Therapeutically

(6) Goers, R.; Thoma, J.; Ritzmann, N.; Di Silvestro, A.; Alter, C.; Gunkel-Grabole, G.; Fotiadis, D.; Müller, D. J.; Meier, W. Optimized Reconstitution of Membrane Proteins Relevant Biomacromolecules. Biomater. Sci. 2015, 3 (1), 25-40. https://doi.org/10.1039/C4BM00230J.

(8) Itel, F.; Chami, M.; Najer, A.; Lörcher, S.; Wu, D.; Dinu, I. A.; Meier, W. Molecular

(7) Itel, F.; Najer, A.; Palivan, C. G.; Meier, W. Dynamics of Membrane Proteins within Synthetic Polymer Membranes with Large Hydrophobic Mismatch. Nano Lett. 2015.

(9) Lichtenberg, D.; Ahyayauch, H.; Alonso, A.; Goñi, F. M. Detergent Solubilization of Lipid Bilayers: A Balance of Driving Forces. Trends Biochem. Sci. 2013, 38 (2), 8593. https://doi.org/10.1016/j.tibs.2012.11.005.

(10) Alibolandi, M.; Ramezani, M.; Abnous, K.; Sadeghi, F.; Hadizadeh, F. Comparative 
Release of Drugs. J. Nanoparticle Res. 2015, 17 (2). https://doi.org/10.1007/s11051015-2878-8.

551

552

553

554

555

556

557

558

559

560

561

562

563

564

565

566

567

568

569

570

571

572

573

(11) Discher, D. E.; Ahmed, F. Polymersomes. Annu. Rev. Biomed. Eng. 2006, 8 (1), $323-$ 341. https://doi.org/10.1146/annurev.bioeng.8.061505.095838.

(12) Patra, S. K.; Alonso, A.; Goñi, F. M. Detergent Solubilisation of Phospholipid Bilayers in the Gel State: The Role of Polar and Hydrophobic Forces. Biochim. Biophys. Acta Biomembr. 1998, 1373 (1), 112-118. https://doi.org/10.1016/S0005-2736(98)00095-9.

(13) Bleul, R.; Thiermann, R.; Maskos, M. Techniques to Control Polymersome Size. Macromolecules 2015, 48 (20), 7396-7409. https://doi.org/10.1021/acs.macromol.5b01500.

(14) Song, Z.; Huang, Y.; Prasad, V.; Baumgartner, R.; Zhang, S.; Harris, K.; Katz, J. S.; Cheng, J. Preparation of Surfactant-Resistant Polymersomes with Ultrathick Membranes through RAFT Dispersion Polymerization. ACS Appl. Mater. Interfaces 2016, 6-10. https://doi.org/10.1021/acsami.6b05847.

(15) Discher, B. M.; Won, Y. Y.; Ege, D. S.; Lee, J. C. M.; Bates, F. S.; Discher, D. E.; Hammer, D. A. Polymersomes: Tough Vesicles Made from Diblock Copolymers. Science (80-. ). 1999, 284 (5417), 1143-1146. https://doi.org/10.1126/science.284.5417.1143.

(16) Le Meins, J. F.; Sandre, O.; Lecommandoux, S. Recent Trends in the Tuning of Polymersomes' Membrane Properties. Eur. Phys. J. E 2011, 34 (2). https://doi.org/10.1140/epje/i2011-11014-y.

(17) LoPresti, C.; Lomas, H.; Massignani, M.; Smart, T.; Battaglia, G. Polymersomes: Nature Inspired Nanometer Sized Compartments. J. Mater. Chem. 2009, 19 (22), 3576-3590. https://doi.org/10.1039/b818869f.

(18) Caruso, F. Modern Techniques for Nano- and Microreactors/-Reactions; Springer: 
Berlin, Heidelberg, 2010. https://doi.org/10.1007/978-3-642-12873-8.

575

576

577

578

579

580

581

582

583

584

585

586

587

588

589

590

591

592

593

594

595

596

597

(19) Pata, V.; Ahmed, F.; Discher, D. E.; Dan, N. Membrane Solubilization by Detergent: Resistance Conferred by Thickness. Langmuir 2004, 20 (10), 3888-3893. https://doi.org/10.1021/la035734e.

(20) Helenius, A.; Simons, K. Solubilization of Membranes by Detergents. Biochim. Biophys. Acta 1975, 415, 29-79. https://doi.org/10.1016/0304-4157(75)90016-7.

(21) Lichtenberg, D.; Ahyayauch, H.; Goñi, F. M. The Mechanism of Detergent Solubilization of Lipid Bilayers. Biophys. J. 2013, 105 (2), 289-299. https://doi.org/10.1016/j.bpj.2013.06.007.

(22) Pizzirusso, A.; De Nicola, A.; Sevink, G. J. A.; Correa, A.; Cascella, M.; Kawakatsu, T.; Rocco, M.; Zhao, Y.; Celino, M.; Milano, G. Biomembrane Solubilization Mechanism by Triton X-100: A Computational Study of the Three Stage Model. Phys. Chem. Chem. Phys. 2017, 19 (44), 29780-29794. https://doi.org/10.1039/c7cp03871b.

(23) Seddon, A. M.; Curnow, P.; Booth, P. J. Membrane Proteins, Lipids and Detergents: Not Just a Soap Opera. Biochimica et Biophysica Acta - Biomembranes. 2004. https://doi.org/10.1016/j.bbamem.2004.04.011.

(24) Mattei, B.; Franca, A. D. C.; Riske, K. A. Solubilization of Binary Lipid Mixtures by the Detergent Triton X-100: The Role of Cholesterol. Langmuir 2015, 31 (1), 378386. https://doi.org/10.1021/la504004r.

(25) Ahyayauch, H.; Bennouna, M.; Alonso, A.; Goñi, F. M. Detergent Effects on Membranes at Subsolubilizing Concentrations: Transmembrane Lipid Motion, Bilayer Permeabilization, and Vesicle Lysis/Reassembly Are Independent Phenomena. Langmuir 2010, 26 (10), 7307-7313. https://doi.org/10.1021/la904194a.

(26) Kragh-Hansen, U.; Maire, M.; Møller, J. V. The Mechanism of Detergent Solubilization of Liposomes and Protein-Containing Membranes. Biophys. J. 1998, 75 
(August), 1-15.

600

601

602

603

604

605

606

607

608

609

610

611

612

613

614

615

616

617

618

619

620

621

622

623

(27) Almgren, M. Mixed Micelles and Other Structures in the Solubilization of Bilayer Lipid Membranes by Surfactants. Biochim. Biophys. Acta - Biomembr. 2000, 1508 (12), 146-163. https://doi.org/10.1016/S0005-2736(00)00309-6.

(28) Lasch, J. Interaction of Detergents with Lipid Vesicles. BBA - Rev. Biomembr. 1995, 1241 (2), 269-292. https://doi.org/10.1016/0304-4157(95)00010-O.

(29) Verchère, A.; Broutin, I.; Picard, M. Reconstitution of Membrane Proteins in Liposomes. Methods Mol. Biol. 2017, 1635 (2000), 259-282. https://doi.org/10.1007/978-1-4939-7151-0_14.

(30) Pata, V.; Ahmed, F.; Discher, D. E.; Dan, N. Membrane Solubilization by Detergent : Resistance Conferred by Thickness. Langmuir 2004, 20 (10), 3888-3893. https://doi.org/10.1021/la035734e.

(31) Wu, D.; Spulber, M.; Itel, F.; Chami, M.; Pfohl, T.; Palivan, C. G.; Meier, W. Effect of Molecular Parameters on the Architecture and Membrane Properties of 3D Assemblies of Amphiphilic Copolymers. Macromolecules 2014, 47 (15), 5060-5069. https://doi.org/10.1021/ma500511r.

(32) Casadei, B. R.; Domingues, C. C.; De Paula, E.; Riske, K. A. Direct Visualization of the Action of Triton X-100 on Giant Vesicles of Erythrocyte Membrane Lipids. Biophys. J. 2014, 106 (11), 2417-2425. https://doi.org/10.1016/j.bpj.2014.04.039.

(33) Habel, J.; Ogbonna, A.; Larsen, N.; Cherré, S.; Kynde, S.; Midtgaard, S. R.; Kinoshita, K.; Krabbe, S.; Jensen, G. V.; Hansen, J. S.; Almdal, K.; Hèlix-Nielsen, C. Selecting Analytical Tools for Characterization of Polymersomes in Aqueous Solution. RSC Adv. 2015, 5 (97), 79924-79946. https://doi.org/10.1039/c5ra16403f.

(34) Yohannes, G.; Jussila, M.; Hartonen, K.; Riekkola, M. L. Asymmetrical Flow FieldFlow Fractionation Technique for Separation and Characterization of Biopolymers and 
Bioparticles. J. Chromatogr. A 2011, 1218 (27), 4104-4116.

625

626

627

628

629

630

631

632

633

634

635

636

637

638

639

640

641

642

643

644

645

646

647

648

https://doi.org/10.1016/j.chroma.2010.12.110.

(35) Kuntsche, J.; Decker, C.; Fahr, A. Analysis of Liposomes Using Asymmetrical Flow Field-Flow Fractionation: Separation Conditions and Drug/Lipid Recovery. J. Sep. Sci. 2012, 35 (15), 1993-2001. https://doi.org/10.1002/jssc.201200143.

(36) Wong, C. K.; Stenzel, M. H.; Thordarson, P. Non-Spherical Polymersomes: Formation and Characterization. Chem. Soc. Rev. 2019, 48 (15), 4019-4035. https://doi.org/10.1039/c8cs00856f.

(37) Hupfeld, S.; Holsaeter, A. M.; Skar, M.; Frantzen, C. B.; Brandl, M. Liposome Size Analysis by Dynamic/Static Light Scattering upon Size Exclusion-/Field FlowFractionation. J. Nanosci. Nanotechnol. 2006, 6 (9-10), 3025-3031. https://doi.org/10.1166/jnn.2006.454.

(38) Hupfeld, S.; Moen, H. H.; Ausbacher, D.; Haas, H.; Brandl, M. Liposome Fractionation and Size Analysis by Asymmetrical Flow Field-Flow Fractionation/Multi-Angle Light Scattering: Influence of Ionic Strength and Osmotic Pressure of the Carrier Liquid. Chem. Phys. Lipids 2010, 163 (2), 141-147. https://doi.org/10.1016/j.chemphyslip.2009.10.009.

(39) Knol, J.; Sjollema, K.; Poolman, B. Detergent-Mediated Reconstitution of Membrane Proteins. Biochemistry 1998, 37 (46), 16410-16415. https://doi.org/10.1021/bi981596u.

(40) Sui, X.; Kujala, P.; Janssen, G. J.; De Jong, E.; Zuhorn, I. S.; Van Hest, J. C. M. Robust Formation of Biodegradable Polymersomes by Direct Hydration. Polym. Chem. 2015, 6 (5), 691-696. https://doi.org/10.1039/c4py01288g.

(41) Liu, J.; Zeng, F.; Allen, C. In Vivo Fate of Unimers and Micelles of a Poly(Ethylene Glycol)-Block-Poly(Caprolactone) Copolymer in Mice Following Intravenous 
Administration. Eur. J. Pharm. Biopharm. 2007, 65 (3), 309-319.

650

651

652

653

654

655

656

657

658

659

660

661

662

663

664

665

666

667

668

669

670

671

672

673 https://doi.org/10.1016/j.ejpb.2006.11.010.

(42) Sun, H.; Mei, L.; Song, C.; Cui, X.; Wang, P. The in Vivo Degradation, Absorption and Excretion of PCL-Based Implant. Biomaterials 2006, 27 (9), 1735-1740. https://doi.org/10.1016/j.biomaterials.2005.09.019.

(43) Piao, L.; Dai, Z.; Deng, M.; Chen, X.; Jing, X. Synthesis and Characterization of PCL/PEG/PCL Triblock Copolymers by Using Calcium Catalyst. Polymer (Guildf). 2003, 44 (7), 2025-2031. https://doi.org/10.1016/S0032-3861(03)00087-9.

(44) Figueiredo, P.; Almeida, B. C.; Carvalho, A. T. P. Enzymatic Polymerization of PCLPEG Co-Polymers for Biomedical Applications. Front. Mol. Biosci. 2019, 6 (October), 1-7. https://doi.org/10.3389/fmolb.2019.00109.

(45) O’Neil, C. P.; Suzuki, T.; Demurtas, D.; Finka, A.; Hubbell, J. A. A Novel Method for the Encapsulation of Biomolecules into Polymersomes via Direct Hydration. Langmuir 2009, 25 (16), 9025-9029. https://doi.org/10.1021/la900779t.

(46) He, X.; Li, L.; Su, H.; Zhou, D.; Song, H.; Wang, L.; Jiang, X. Poly(Ethylene Glycol)Block-Poly( $\varepsilon$-Caprolactone)-and Phospholipid-Based Stealth Nanoparticles with Enhanced Therapeutic Efficacy on Murine Breast Cancer by Improved Intracellular Drug Delivery. Int. J. Nanomedicine 2015, 10, 1791-1804. https://doi.org/10.2147/IJN.S75186.

(47) Pang, Z.; Gao, H.; Yu, Y.; Guo, L.; Chen, J.; Pan, S.; Ren, J.; Wen, Z.; Jiang, X. Enhanced Intracellular Delivery and Chemotherapy for Glioma Rats by TransferrinConjugated Biodegradable Polymersomes Loaded with Doxorubicin. Bioconjug. Chem. 2011, 22 (6), 1171-1180. https://doi.org/10.1021/bc200062q.

(48) Zou, T.; Dembele, F.; Beugnet, A.; Sengmanivong, L.; Trepout, S.; Marco, S.; Marco, A. de; Li, M. H. Nanobody-Functionalized PEG-b-PCL Polymersomes and Their 

https://doi.org/10.1016/j.jbiotec.2015.09.034.

676

677

678

679

680

681

682

683

684

685

686

687

688

689

690

691

692

693

694

695

696

697

698

(49) Lu, F.; Pang, Z.; Zhao, J.; Jin, K.; Li, H.; Pang, Q.; Zhang, L.; Pang, Z. Poly ( $\varepsilon^{-}$ Caprolactone ) Polymersomes for Dual- Targeting Drug Delivery to Glioma in Rats. Int. J. Nanomedicine 2017, 12, 2117-2127.

(50) Hannesschläger, C.; Barta, T.; Siligan, C.; Horner, A. Quantification of Water Flux in Vesicular Systems. Sci. Rep. 2018, 8 (1), 1-8. https://doi.org/10.1038/s41598-01826946-9.

(51) Gan, H. X.; Zhou, H.; Lin, Q.; Tong, Y. W. Quantification of Aquaporin-Z Reconstituted into Vesicles for Biomimetic Membrane Fabrication. Sci. Rep. 2017, 7 (1), 1-13. https://doi.org/10.1038/s41598-017-11723-x.

(52) Blundell, E. L. C. J.; Vogel, R.; Platt, M. Particle-by-Particle Charge Analysis of DNA-Modified Nanoparticles Using Tunable Resistive Pulse Sensing. Langmuir 2016, 32 (4), 1082-1090. https://doi.org/10.1021/acs.langmuir.5b03024.

(53) Thiyagarajan, P.; Tiede, D. M. Detergent Micelle Structure and Micelle-Micelle Interactions Determined by Small-Angle Neutron Scattering under Solution Conditions Used for Membrane Protein Crystallization. J. Phys. Chem. 1994, 98 (40), 10343-10351. https://doi.org/10.1021/j100091a058.

(54) Garcia, D.; Parot, P.; Verméglio, A.; Madigan, M. T. The Light-Harvesting Complexes o f a Thermophilic Purple Sulfur Photosynthetic Several Biophysical Properties ( Absorption , Fluorescence, Linear Dichroism ) Are Reported for the Chromato- Phore Membranes of the Thermophilic Purple Sulfur Bacterium, Chr. Biochim. Biopl vsica A cta 1986, 850, 390-395.

(55) Kotov, V.; Bartels, K.; Veith, K.; Josts, I.; Subhramanyam, U. K. T.; Günther, C.; Labahn, J.; Marlovits, T. C.; Moraes, I.; Tidow, H.; Löw, C.; Garcia-Alai, M. M. 
High-Throughput Stability Screening for Detergent-Solubilized Membrane Proteins. Sci. Rep. 2019, 9 (1), 1-19. https://doi.org/10.1038/s41598-019-46686-8.

(56) Arachea, B. T.; Sun, Z.; Potente, N.; Malik, R.; Isailovic, D.; Viola, R. E. Detergent Selection for Enhanced Extraction of Membrane Proteins. Protein Expr. Purif. 2012, 86 (1), 12-20. https://doi.org/10.1016/j.pep.2012.08.016.

(57) Lichtenberg, D.; Opatowski, E.; Kozlov, M. M. Phase Boundaries in Mixtures of Membrane-Forming Amphiphiles and Micelle-Forming Amphiphiles. Biochim. Biophys. Acta - Biomembr. 2000, 1508 (1-2), 1-19. https://doi.org/10.1016/S03044157(00)00004-6.

(58) Alonso, A.; Urbaneja, M. A.; Goñi, F. M.; Carmona, F. G.; Cánovas, F. G.; GómezFernández, J. C. Kinetic Studies on the Interaction of Phosphatidylcholine Liposomes with Triton X-100. BBA - Biomembr. 1987, 902 (2), 237-246. https://doi.org/10.1016/0005-2736(87)90301-4.

(59) Li, J.; Wang, X.; Zhang, T.; Wang, C.; Huang, Z.; Luo, X.; Deng, Y. A Review on Phospholipids and Their Main Applications in Drug Delivery Systems. Asian J. Pharm. Sci. 2015, 10 (2), 81-98. https://doi.org/10.1016/j.ajps.2014.09.004.

(60) Ravve, A. Principles of Polymer Chemistry, Third Edit.; Ravve, A., Ed.; Springer Science + Business Media, LLC: Niles, IL, USA, 2012. https://doi.org/10.1007/978-14614-2212-9.

(61) Srinivas, G.; Shelley, J. C.; Nielsen, S. O.; Discher, D. E.; Klein, M. L. Simulation of Diblock Copolymer Self-Assembly, Using a Coarse-Grain Model. J. Phys. Chem. B 2004, 108 (24), 8153-8160. https://doi.org/10.1021/jp037842f.

(62) Doi, M. Introduction to Polymer Physics; Carendon Press, Oxford: Tokyo, Japan, 1996.

(63) Beales, P. A.; Khan, S.; Muench, S. P.; Jeuken, L. J. C. Durable Vesicles for 
Reconstitution of Membrane Proteins in Biotechnology. Biochem. Soc. Trans. 2017, 45 (1), 15-26. https://doi.org/10.1042/BST20160019.

726

(64) Mimms, L. T.; Zampighi, G.; Nozaki, Y.; Tanford, C.; Reynolds, J. A. Phospholipid Vesicle Formation and Transmembrane Protein Incorporation Using Octyl Glucoside. Biochemistry 1981, 20 (4), 833-840. https://doi.org/10.1021/bi00507a028.

(65) Nallani, M.; Benito, S.; Onaca, O.; Graff, A.; Lindemann, M.; Winterhalter, M.; Meier, W.; Schwaneberg, U. A Nanocompartment System (Synthosome) Designed for Biotechnological Applications. J. Biotechnol. 2006, 123 (1), 50-59.

732 https://doi.org/10.1016/j.jbiotec.2005.10.025.

(66) Weinhold, F.; West, R. The Nature of the Silicon-Oxygen Bond. Organometallics 2011, 30 (21), 5815-5824. https://doi.org/10.1021/om200675d. 